which found many senior medics regard such training as potentially worthless.

It should be remembered that it is senior colleagues who conduct Mental Health Act assessments on acutely disturbed patients within the community. Indeed, my study revealed that a quarter of consultants had been directly involved in incidents of patient aggression within the previous year.

Inadequate environmental safety provision for psychiatric staff is commonplace. It is unfortunate therefore, that Dibben et al's study discovered many medics avoid wearing personal alarms even when available, instead relying upon defensive skills of colleagues in an emergency. The Royal College of Psychiatrists and NHS trusts should jointly seek to improve safety provisions. However, I believe 'personal safety' is just that - the responsibility of individual healthcare workers, regardless of discipline or seniority and one should not expect to defer this entirely to colleagues or their employers.

NHS SECURITY MANAGEMENT SERVICE (2005) Promoting Safer and Therapeutic Services. Department of Health (http://www.cfsms.nhs.uk/ doc/psts/psts.implementing.syllabus.pdf).

Sara Adshead Specialist Registrar in General Adult Psychiatry, Newington Centre, Newington Road, Of Hamar Way, Marston Green, Birmingham BS37 7RW email: sara.adshead@bsmht.nhs.uk

doi: $10.1192 / \mathrm{pb} .32 .6 .233 \mathrm{c}$

\section{NICE guidance on joint decision for treatment of acute mania: completed audit cycle}

In 2003, National Institute for Health and Clinical Excellence (NICE) recommended that, 'The choice of drugs prescribed in acute mania should be made jointly by the individual and the clinician(s) responsible for treatment. [It] should be based on an informed discussion of the relative benefits and side-effect profiles of each drug, and should take into account the needs of the individual and the particular clinical situation. In all situations where informed discussion is not possible, advance directives should be taken fully into account and the individual's advocate and/or carer should be consulted when appropriate' (NICE, 2003)

We completed an audit cycle to examine the compliance with this recommendation. After discussion with the clinicians locally, it was agreed that any documentation indicative of a discussion on drug selection between the clinician and the patient or his/her advocate/carer, or reference to the advance directives, will be accepted as the standard.

The first phase of the audit cycle was conducted in 2004. The in-patient notes of the adult patients admitted with acute mania were searched for the above information or documentation of capacity assessment.

The results and the recommendations from the first cycle were presented at the local educational meeting and a report was submitted to the trust audit department to be circulated to all the clinicians and made available on the intranet. The re-audit was conducted in 2006.

In 2004, out of a total of 38 case notes examined, only $13 \%$ had any documentation towards joint decision on drug selection. In 2006, 32 case notes were examined and $40 \%$ of these had joint decision documentation. None of the case notes (in 2004 and 2006) had any reference of capacity to consent, advanced directives or discussion with carers.

It is possible that the joint discussions on the selection of drugs are held but not documented for various reasons, for example lack of time or ignorance. The patients might lack capacity due to severity of their illness and the relative or carer might not be available to give consent. In both phases of audit cycle, more than half of the patients $(55 \%$ in 2004 and $66 \%$ in 2006) were detained under the Mental Health Act 1983 and about a third (29\% in 2004 and $37 \%$ in 2006) required admission to the psychiatric intensive care unit reflecting the severity of illness. Nevertheless, the Mental Health Act code of practice clearly indicates that a detained individual is not necessarily incapable of giving consent and the interview at which their consent for treatment was sought as well as assessments of their capacity should be fully documented in the patient's notes

It will be interesting to hear views and experiences of other clinicians in this area.

NATIONAL INSTITUTE FOR CLINICAL EXCELLENCE 2003) Olanzapine and valproate semisodium in the treatment of acute mania associated with bipolar | disorder. TA66 Bipolar disorder - new drugs: Guidance. NICE.

DEPARTMENT OF HEALTH \& WELSH OFFICE (1999) Code of Practice. Mental Health Act. HMSO

Kamini Vasudev Specialist Registrar, Genera Adult Psychiatry, Hadrian Clinic, Newcastle General Hospital, Newcastle uponTyne NE4 6BE, email: kaminivasudev@hotmail.com, Pratish Thakkar ST4 Forensic Psychiatry, Bamburgh Clinic, St Nicholas Hospital, Newcastle uponTyne, Stephen Martin Consultant Psychiatrist, County Hospital Durham, Durham

doi: $10.1192 / p b .32 .6 .234$

\section{Opportunity for training beyond the NHS in the voluntary sector}

Nimmagadda et al (Psychiatric Bulletin, February 2008, 32, 41-43) argue for psychiatric trainees to have more exposure to training opportunities in the independent sector. We agree with their arguments but would specifically encourage trainees to consider training opportunities in the voluntary sector. In our experience voluntary training sessions at the Medical Foundation for the Care of Victims of Torture in London have been an experience rewarding both professionally and personally.

At a time when there are concerns about the quality of job plans and special interest sessions, time spent with the Medical Foundation provided valuable experience in psychotherapy not routinely available in the NHS - for example, working with former child soldiers.

The voluntary sector can also provide experience in working outside of the NHS management systems. Looking from the outside in at various parts of the service can positively inform future dealings with the independent sector (Nimmagadda et al, 2008).

Burnout among medical specialists has been found to be experienced as a combination of a high level of stress and a low level of job satisfaction, rather than as stress alone (Visser, 2003). By allowing the trainee to contribute to a worthwhile cause relevant to them, voluntary work can increase a trainee's overall sense of job satisfaction and prevent burnout.

Recent concerns have also been raised about the return of a career bottleneck for psychiatric trainees (Goldberg, 2007). Voluntary work allows the trainee to take responsibility for their own training and will increase their career prospects by enhancing their CV

The possibilities for psychiatric training in the voluntary sector are many and varied. We would encourage trainees and the College to embrace these opportunities.

GOLDBERG, D. (2007) Improved investment in mental health services: value for money? British Journal of Psychiatry, 192, 88-91.

VISSER, M., SMETS, E. M., OORT, F. J., et al (2003) Stress, satisfaction and burnout among Dutch medical specialists. Canadian Medical Association Journal, 168, 271-275.

*Jim Crabb Specialist Registrar, Greater Glasgow and Clyde NHS Trust, Esteem, Unit 21-21 Hydepark Business Centre, 60 Mollison Street, Glasgow G214SF, email: drjimcrabb@yahoo.co.uk, William Hopkins Consultant Psychiatrist and Psychotherapist, Medical Foundation London

doi: $10.1192 / p b .32 .6 .234 a$ 